\title{
Consumer reactions to risk information on bovine spongiform encephalopathy in Japan
}

\author{
Kumiko Ogoshi $\cdot$ Hideo Yasunaga $\cdot$ \\ Naoya Obana $\cdot$ Toshio Ogawa $\cdot$ Tomoaki Imamura
}

Received: 25 June 2009/Accepted: 29 March 2010/Published online: 28 April 2010

(c) The Japanese Society for Hygiene 2010

\begin{abstract}
Objectives To investigate the impact of information on foodborne disease on consumers, we quantified consumers' anxiety, purchasing behaviors, and willingness-to-pay (WTP) in response to the reading of newspaper articles published in 2001 that documented the first cow in Japan to be infected with bovine spongiform encephalopathy (BSE). Methods An online questionnaire survey of 993 females aged 20-59 years was conducted in 2007. The participants were randomly selected from the general population via the Internet and were divided into three groups. Each group was assigned a different number of BSE-related articles to read, namely, two, four, and six articles, respectively. Each participant described her personal level of anxiety, underlying reasons for her anxiety, and changes in purchasing behavior after reading the articles. The respondents who wanted to buy guaranteed-safe beef were asked to state their maximal WTP.

Results The level of anxiety was significantly lower and distrust of the relevant administration significantly greater in the group asked to read six articles than in the other groups. The WTP value for guaranteed beef was approximately 1.3 -fold higher than the regular purchase price, with
\end{abstract}

K. Ogoshi $(\bowtie) \cdot$ T. Ogawa $\cdot$ T. Imamura

Department of Public Health, Health Management and Policy,

Nara Medical University, 840 Shijo-cho, Kashihara,

Nara 634-8521, Japan

e-mail: kogoshi@naramed-u.ac.jp

H. Yasunaga

Department of Health Management and Policy, Graduate School of Medicine, University of Tokyo, Tokyo, Japan

N. Obana

Human-Care Research Group, Mitsubishi Research Institute Inc.,

Tokyo, Japan significant differences between groups. In the 'six-article' group, the ratio between WTP and the regular purchase price was significantly less than that in the 'four-article' group.

Conclusions These findings suggest that the anxiety of consumers can be reduced if they receive an appropriate amount of published information. WTP may be linked to the contents of the articles.

Keywords Bovine spongiform encephalopathy . BSE - Consumer · Risk communication .

Willingness-to-pay

\section{Introduction}

Bovine spongiform encephalopathy (BSE) is caused by an abnormal prion protein and is associated with human variant Creutzfeldt-Jakob disease (vCJD) [1]. BSE was first detected in the UK in 1986, while the first BSE-infected dairy cow in Japan was identified in September 2001 [2].

In Japan, concern over various foodborne diseases has caused public health crises at different times in the past [3]. The BSE incident in Japan in 2001 was, however, considerably different from those associated with these earlier incidents because it created an unusually large panic among the general population-even though there had been no deaths or cases of illness caused by BSE in Japan at that time. Some cattle farmers and food processors even committed suicide because of concern about the economic damage caused by the BSE incident and increased consumer restraint in purchasing beef.

One reason why the Japanese government was unable to prevent this tragic development is that the dissemination of information to the public on the risk of BSE was 
inadequate. The aim of risk communication is to share information on the probability of adverse outcomes described in health and scientific assessments and the degree of risk in order to form a consensus among stakeholders, including the government, experts on risk analysis, enterprises and consumers. In Japan, sensational reports in the media on the first occurrence of BSE in 2001 seemed to cause a state of panic among consumers.

Even though the panic induced by BSE is a well-known event in Japan, to date there has been no analysis of the impact of the media on consumer behavior during this 'panic' period. Takeshita analyzed the effect of health information on food consumption using the example of salad oil consumption and concluded that consumers' concerns are influenced by the information they receive, with the extent of the influence increasing rather than decreasing consumers' concerns [4]. Sawada compared two episodes of mass food poisoning that occurred in 1996, namely, the contamination of food with the pathogenic Escherichia coli $\mathrm{O} 157$ that occurred in Japan and the mad cow disease epidemic that occurred among cattle in the UK. Notably, he found that mad cow disease did not affect the purchase of beef in Japan [5].

Since the occurrence of BSE, willingness-to-pay (WTP) approaches have been commonly used in Japan as a method to evaluate the perceived safety of beef [6-8]. Giamalva et al. [9] used the WTP approach to investigate dietitians' acceptance of three methods to reduce the risk of foodborne disease, namely the Hazard Analysis and Critical Control Point (HACCP) system, chemical washing, and irradiation. They reported that dietitians were most accepting of the HACCP system, less accepting of irradiation, and least accepting of new chemical washes. Frenzen et al. [10] conducted a study to assess consumers' acceptance of irradiated meat and poultry using WTP, and van der Pol et al. [11] also examined consumers' concern for food safety by assessing the individuals' WTP to eliminate the risk of poultry-borne illness by irradiation or a hypothetical treatment.

The purpose of this study was to investigate the effects of reading BSE-related newspaper articles and the implementation of measures to protect against BSE on consumer behavior, anxiety, and WTP for safe beef.

\section{Materials and methods}

Article selection

To quantify the level of anxiety induced by the mass media, we first identified the BSE panic period based on the number of BSE-related articles written in the five major Japanese-language newspapers published in Japan (Yomiuri,
Asahi, Mainichi, Nikkei, and Sankei) in September and October 2001. The total length of the articles was also measured by counting the number of characters in each article.

Presentation of the relevant articles

Six BSE-related articles that appeared in the Yomiuri, Asahi, and Mainichi newspapers during the identified panic period between September 11 and October 17, 2001 were selected for the questionnaire survey. A summary of the six articles is shown in the Appendix.

Article 1 reported that a dairy cow in Chiba prefecture had BSE. Article 2 reported the decision by the Ministry of Agriculture, Forestry, and Fisheries (MAFF) to conduct a nationwide survey of all cows and cattle with BSE-related neurological symptoms. Article 3 stated that the report by the MAFF, which stated that the infected cow had already been culled, was an error and that this cow was processed into meat and bone meal. Article 4 reported the implementation of testing procedures for all cows and cattle by the Ministry of Health, Labour and Welfare (MHLW). Article 5 reported that, regarding the publication of the results of the screening tests, the decisions made by the MHLW changed frequently. Article 6 reported that falsepositive cows would not be shipped until their safety was confirmed.

\section{Questionnaire survey}

\section{Sample collection}

An online questionnaire survey was conducted via the Internet in 2007. We used an Internet survey for two main reasons: (1) to prevent consumers from answering questions without reading the presented information; (2) to allow for the collection of responses from a large number of individuals within a short period of time (several days). We selected a sample group of Japanese females aged 20-59 years old residing in Japan. This age group was chosen based on the assumption that, in Japan, it is this demographic group that generally purchases beef as a food. In contrast, only a small number of men purchase and cook beef. Furthermore, beef is less popular among people aged 60 years or older because they tend to prefer fish and chicken for health reasons.

To conduct this survey, we collaborated with an Internet research company, Goo (Tokyo, Japan), which has approximately 356,000 registered Internet users, with women accounting for half of these users $(179,000)$. We randomly selected 3,040 women aged 20-59 years who were registered on the Goo database and sent an E-mail to each participant on March 23, 2007, inviting them to 
participate in the survey. The invited participants were asked to voluntarily access the online questionnaire shown in Table 1. Over a 5-day period from March 23 to March 27, 2007, a total of 993 people responded to the survey, giving a response rate of $32.7 \%$.

The survey included questions on annual household income and preference for beef as the determinants of purchase price of beef. We did not include questions on other factors that may affect the purchase of beef, such as education and profession, marriage status, family make-up, and presence of diseases in the participants or their family members, for a number of reasons. First, past experience has revealed that questions on education, profession, and marriage status decrease the response rate. Second, we considered that analyses on family make-up and the presence of diseases in subjects and their family members were of limited utility in a group of about 1,000 subjects.

Institutional review board approval was not necessary because this research was based on an anonymous, selfadministered questionnaire for the general public. The cover letter of the questionnaire provided the subjects with the following information: (1) data collection and analysis was fully anonymous and their private information would be completely protected; (2) all answers would be kept confidential, processed statistically, and used only for this scientific study; (3) they could either participate voluntarily or refuse to participate.

\section{Grouping}

The participants $(n=993)$ were randomly divided into three groups and stratified based on age ranges. Group A participants $(n=330)$ were sent articles 1 and 2, Group B $(n=333)$ participants were sent articles 1,2,3, and 4, and Group C participants $(n=330)$ were sent all six of the chosen articles. Each participant was asked to read the designated articles and to complete the accompanying questionnaire.

\section{Questionnaire}

After reading the articles, participants were questioned about the degree to which they felt anxiety using a fourpoint Likert scale: strongly $($ score $=3$ ); considerably (score $=2)$; slightly $($ score $=1)$; none $($ score $=0)$. The respondents who answered that "I felt anxiety", then were asked to describe the cause of this anxiety by choosing the most appropriate item from among the following six choices: (1) route of BSE infection is still unknown; (2) BSE also occurred in Japan; (3) I might have eaten BSE-infected beef; (4) the number of BSEinfected cows might be increasing in Japan; (5) I doubt the credibility of the presented information itself; (6) I distrust the government.

To obtain an assessment of changes in purchasing behavior of beef after reading the articles, we asked the respondents to select one of the following responses: "My purchasing pattern will not change", "I will reduce my purchasing pattern", "I will only buy beef whose safety is guaranteed", or "I will not buy beef at all".

All participants were also questioned about their preference for beef, frequency of purchasing beef, and the average unit price of beef they usually buy (i.e., "How much did you pay per $100 \mathrm{~g}$ of beef before you read the newspaper articles?"), and their annual household income.

\section{Willingness-to-pay measurement}

The respondents who answered "I will only buy beef whose safety is guaranteed" were asked to state their maximum WTP for $100 \mathrm{~g}$ of 'safe' beef. The open-ended question "If safe BSE-free beef was available, how much would you be willing to pay for it?" was used to determine the WTP values. This question did not differentiate types or quality of beef, such as between Japanese black cattle and other Japanese beef. The average ratio between WTP and regular purchase prices was also calculated.

Table 1 Participant backgrounds

\begin{tabular}{llll}
\hline Participant characteristics & Group A $(n=330)$ & Group B $(n=333)$ & Group C $(n=330)$ \\
\hline Average age, years $( \pm$ SD) & $38.38 \pm 10.51$ & $38.78 \pm 10.36$ & $38.58 \pm 10.74$ \\
Average income $( \pm$ SD) $¥ ¥ 1,000)$ & $6,268 \pm 2,628$ & $6,249 \pm 2,703$ & $6,265 \pm 2,662$ \\
Preference for beef & & & 281 \\
Like & 272 & 272 & 27 \\
Neither & 36 & 37 & 22 \\
Dislike & 22 & 24 & $352 \pm 201(n=287)$ \\
Regular purchase price of beef $(¥ / 100 \mathrm{~g})$ & $345 \pm 199(n=294)$ & $366 \pm 216(n=298)$ & \\
\hline
\end{tabular}

SD Standard deviation

No significant differences were noted for any item $(P<0.05)$ 
Statistical analysis

Chi-square tests were used to compare anxiety scores, reasons for feeling anxiety, and changes in purchasing behavior among groups. One-way analysis of variance (ANOVA) was used to compare the mean values of age, annual income, regular purchase price, and anxiety scores. Differences between groups for WTP and the ratio between WTP and regular purchase price were evaluated by ANOVA and Turkey's HSD post hoc test. Factors affecting WTP were analyzed by categorical regression analysis. All statistical analyses were performed using SPSS ver. 14.0 (SPSS, Chicago, IL). $P$ values $<0.05$ were considered to be significant.

\section{Results}

Figure 1 shows the number of BSE-related articles and the total number of characters in these articles. A spiked increase in the number of articles was found on the days when the newspapers reported the first BSE-infected cow on September 11, the erroneous publication by the MAFF on September 15, and the frequent changes in the MHLW's decisions on October 13.

Table 1 shows the participants' backgrounds in each group. There were no significant differences in terms of mean age, annual income, preference for beef, or regular purchase price of beef among the three groups.

Table 2 shows the level of anxiety caused by reading designated articles according to the three groups. The anxiety scores were different among the three groups $(P<0.002)$, with significant differences noted between Groups A and C and between Groups B and C. The average anxiety score was significantly lower in Group C (1.70) than in groups A (1.98) or B (1.92) $(P<0.05)$.

The reasons for anxiety differed between the three groups, as shown in Table 2. The most common reasons for

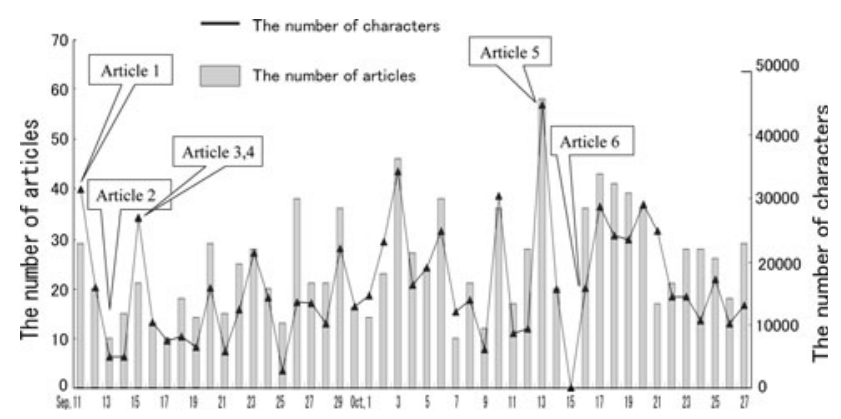

Fig. 1 The number of newspaper articles and the total number of characters devoted to bovine spongiform encephalopathy (BSE) in September and October, 2001 anxiety among Group A participants were "Route of BSE infection is still unknown" and "BSE also occurred in Japan". "Route of BSE infection is still unknown" was more commonly cited in Group A than in Groups B and C, and in Group B than in Group C. No difference was noted between Groups A and B for "BSE also occurred in Japan", "I might have eaten BSE-infected beef", "the number of BSE-infected cows might be increasing in Japan", and "I distrust the government". However, participants in Group B were more likely to answer "I might have eaten BSE-infected beef" and "the number of BSE-infected cows might be increasing in Japan". The rates for the first four items were significantly lower and the remaining two items, "I doubt the credibility of the presented information itself" and "I distrust the government", were significantly higher in Group C than in Groups A and B.

In terms of the change in purchasing behavior after reading the articles, the statistical analysis showed a nearsignificant difference at $P<0.055$. Thus, we concluded that there was little difference when a significance level of $P<0.05$ was used. However, nearly $40 \%$ of people in Group C reported "No change", whereas Group B individuals were more likely to respond "I will buy less beef" and "I will only buy beef whose safety is guaranteed".

As shown in Table 3, 197 participants provided a WTP for safe beef (67 from Group A, 70 from Group B, and 57 from Group C). There were no differences between groups in terms of annual household income, preference for beef, and age for the WTP respondents. The average WTP values $( \pm \mathrm{SD})$ for safe beef were $¥ 391 \pm 264$, $¥ 491 \pm 256$, and $¥ 400 \pm 230$ for Groups A, B, and C individuals, respectively. The average WTP among Group B individuals was slightly, but not significantly, higher than that among Group A participants $(P<0.10)$. In addition, categorical regression analysis showed significant differences between groups in terms of annual household income and preference for beef (Table 4). Of those who stated a WTP, 60, 66, and 51 participants in Groups A, B, and C, respectively, also stated their regular purchase price. The ratio between WTP and the regular purchase price was significantly lower in Group C than in Group B based on Turkey's HSD post hoc test (Table 5), although there was little difference between groups using ANOVA $(P=0.055)$.

\section{Discussion}

In Europe, BSE-related newspaper articles have been reported to have had a large effect on beef consumption behavior. Miller [12] found that there were two peaks for trends in BSE reports in British national newspapers over the 9 years from 1988 to 1996, with the first peak 
Table 2 Anxiety caused by reading the articles

\begin{tabular}{|c|c|c|c|}
\hline & $\begin{array}{l}\text { Group A } \\
(n=330)\end{array}$ & $\begin{array}{l}\text { Group B } \\
(n=333)\end{array}$ & $\begin{array}{l}\text { Group C } \\
(n=330)\end{array}$ \\
\hline Anxiety score & \multicolumn{3}{|c|}{$* * *$} \\
\hline Score $=3$ (felt strong anxiety) & $96(29.1 \%)$ & $90(27.0 \%)$ & $69(20.9 \%)$ \\
\hline Score $=2$ (felt considerable anxiety) & $144(43.6 \%)$ & $145(43.5 \%)$ & $129(39.1 \%)$ \\
\hline Score $=1$ (felt slight anxiety) & $77(23.3 \%)$ & $80(24.0 \%)$ & $96(29.1 \%)$ \\
\hline Score $=0$ (felt no anxiety) & $13(3.9 \%)$ & $18(5.4 \%)$ & $36(10.9 \%)$ \\
\hline \multirow[t]{2}{*}{ Average score } & 1.98 & & \\
\hline & Group A & Group B & Group C \\
\hline Route of BSE infection is still unknown. & \multicolumn{3}{|c|}{$279(\underbrace{(88.0 \%)_{*} 260}_{*}(82.5 \%)_{* *}^{221}(75.2 \%)$} \\
\hline BSE also occurred in Japan. & \multicolumn{3}{|c|}{$274(86.4 \%) 271(\underset{* 6.0 \%) 230}{(86 * *}(78.2 \%)$} \\
\hline I might have eaten BSE-infected beef. & \multicolumn{3}{|c|}{$\frac{271(85.5 \%) 279(88.6 \%)_{* *}^{238}(8)}{(81.0 \%)}$} \\
\hline \multicolumn{4}{|c|}{ Number of BSE-infected cows might be increasing in Japan. 175 (55.2\%) $197(62.5 \%)_{13 *}(59(54.1 \%)$} \\
\hline I doubt the credibility of the presented information itself. & \multicolumn{3}{|c|}{$74(23.3 \%) * \underset{* * *}{97}(30.8 \%) * 125(42.5 \%)$} \\
\hline \multirow[t]{2}{*}{ I distrust the government. } & \multicolumn{3}{|c|}{$120(\underbrace{(37.9 \%) 144)_{* *}^{(45.7 \%) 181}}_{* * *}(61.6 \%)$} \\
\hline & Group A & Group B & Group C \\
\hline No change. & $119(36.1 \%)$ & $113(33.9 \%)$ & $130(39.4 \%)$ \\
\hline I will buy less beef. & $72(21.8 \%)$ & $90(27.0 \%)$ & $86(26.1 \%)$ \\
\hline I will only buy beef whose safety is guaranteed. & $67(20.3 \%)$ & $70(21.0 \%)$ & $57(17.3 \%)$ \\
\hline I will stop purchasing beef. & $72(21.8 \%)$ & $60(18.0 \%)$ & $57(17.3 \%)$ \\
\hline
\end{tabular}

I will only buy beef whose safety is guaranteed.
$B S E$ Bovine spongiform encephalopathy

$* p<0.05$

$* * p<0.01$

$* * * p<0.001$

(a)


Table 5 Difference between WTP and regular purchase price

\begin{tabular}{lll}
\hline Group & $n$ & $\begin{array}{l}\text { Ratio between WTP and regular } \\
\text { purchase price }^{\mathrm{a}}\end{array}$ \\
\hline $\mathrm{A}$ & 60 & $1.35 \pm 0.41$ \\
$\mathrm{~B}$ & 66 & $1.46 \pm 0.53^{\mathrm{b}}$ \\
$\mathrm{C}$ & 51 & $1.27 \pm 0.35^{\mathrm{b}}$ \\
\hline
\end{tabular}

${ }^{a}$ Regular purchase price $=1$. Values are given as the mean \pm SD

${ }^{\mathrm{b}}$ Ratio between WTP and the regular purchase price was significantly lower $(P<0.05)$ in Group $C$ than in Group B based on Turkey's HSD post hoc test

2 (felt considerable anxiety; Table 2), which was similar to the results of the studies in Europe, as described above.

We also demonstrated that anxiety can be reduced by providing the consumers with more information because the anxiety score was lowest in Group C $(=1.70)$, followed by Group B $(=1.92)$ and A $(=1.98)$. This may be explained by the amount of the information provided.

The participants in Group C were asked to read all six articles and then asked to state their anxiety after reading articles 1 and 2, and then after reading articles 3 and 4 . More than $95 \%$ of participants in Group C felt levels of anxiety after reading articles 1 and 2 and after then reading articles 3 and 4 as well that were similar to that experienced by Group A and B participants, respectively. Therefore, we conclude that articles 1-4 had similar impacts on all three groups, while reading articles 5 and 6 drove the different impacts in Group C. Thus, these differences may be explained by the amount of information provided.

In terms of the reasons for feeling anxiety, the most frequent answer of Group A individuals was "Route of BSE infection is still unknown", with $88.0 \%$ providing a positive response, followed by "BSE occurred in Japan" and "I might eat BSE-infected beef". In Group B, 88.6\% of the participants answered "I might eat BSE-infected beef", followed by "BSE also occurred in Japan". The responses "I doubt the credibility of the presented information itself" and "I distrust the government" were more frequently reported by Group $\mathrm{C}$ participants than by those in Groups $\mathrm{A}$ and $\mathrm{B}$.

In terms of the change in purchasing behavior after reading the articles, the percentage of participants who reported "no change" was highest in Group C. In contrast, "I will buy only beef whose safety is guaranteed" and "I will stop purchasing beef" were less frequently reported in Group C than in Groups A and B.

Based on these results, it can be concluded that both the content and the amount of information available greatly influence changes in purchasing behavior; this effect is particularly evident in Group C. Articles 5 and 6, which reported that the false-positive results in the screening tests occurred at a constant rate and that the distribution to the market would be stopped until the results were confirmed as negative by decisive diagnosis, had less impact and caused less anxiety than the first four articles. Furthermore, although articles 5 and 6 reduced the level of anxiety over beef itself, they expressed increased distrust in the government and in the information being released to the public. Further analysis is needed to determine the effects of the content of Articles 5 and 6 and the reasons underlying the lower anxiety score among Group $\mathrm{C}$ participants.

The results of this survey show that the average regular purchase price was about $¥ 350$. In 2007 , the same year as our survey was conducted, Yamane conducted a monitoring survey among Japanese females in their 30 s and 50s to examine the changes in purchasing behaviors when the blanket testing of all cattle was continued or when tests on cattle aged $\leq 20$ months were discontinued. In their study, the purchase price of domestic beef was $¥ 295$ per $100 \mathrm{~g}$. However, as described by Yamane, this price was lower than the regular price because most of the subjects purchased beef during a period of low prices [8]. Iwamoto et al. [6] reported that the average purchase price of beef was $¥ 328$ per $100 \mathrm{~g}$. Thus, the average regular purchase price stated by the participants in our survey was comparable with those in these earlier studies.

The average WTP in the full study sample was about $¥ 430$ per 100 g. In 2001, McCluskey et al. [7] calculated that the price premium, i.e., the difference from the average purchase price, would be increased by $50 \%$ because 244 of 381 respondents in their study stated that they would pay a premium for safe food and for safety supported by testing. Iwamoto et al. [6], surveyed 1,536 individuals in 2002 with respect to their WTP for traceable beef and estimated an increase of $¥ 18(5.6 \%)$ in average WTP (average purchase price: $¥ 328$ per $100 \mathrm{~g}$ ). Thus, the WTP for safe beef ranges from 5 to $50 \%$. Unfortunately, we cannot compare our WTP estimates with those reported by McCluskey et al. [7] or Iwamoto et al. [6] because ours were reported by the respondents themselves, while the WTP values reported by McCluskey et al. and Iwamoto et al. were estimates. However, our results (WTP-average purchase price $=$ $¥ 118$, which is an increase of $30 \%$ ) are valid because they fall within the range of the values of McCluskey et al. and Iwamoto et al.

The categorical regression analysis revealed significant differences between the three groups (Table 4), although Turkey's HSD post hoc test did not (Table 3 ). The differences between these methods can be explained by the fact that WTP tends to be biased by the household income and the preference for beef, which were adjusted for in the categorical regression analysis. Table 5 also demonstrates that group B participants had the highest ratio between WTP and the regular purchase price. Overall, it seems that the WTP was increased by reading articles related to the 
BSE incidence and decreased by reading additional articles.

We estimated consumers' WTP to quantify their "desire for safe beef". However, as shown here, the WTP for safe beef is not related to the degree of anxiety. Instead, WTP may be linked to the contents of articles that are read. Participants in Group $\mathrm{C}$ reported lower anxiety scores after reading articles 5 and 6 which expressed an increased distrust of the government and of the information being provided by the government. WTP and the ratio between WTP and the regular purchase price were greatest among Group B participants, which may be due to the contents of the articles, which influenced WTP, rather than the number of articles read. In other words, the expressed distrust of the government reduced the desire for safe beef and lowered the WTP in Group C. De Jonge et al. [14] reported that distrust of the institutions responsible for ensuring the safety of beef and fish could cause the consumers to become unsure of food safety. Yamane calculated that discontinuation of blanket BSE testing would lower the price premium by $25.68 \%$ [8]. These results suggest that the distrust of the government reduced the desire for safe beef and lowered the WTP in Group C participants.

The questionnaire used in our study did not differentiate between Japanese black cattle beef and other Japanese beef, whereas Aizaki et al. [15] conducted a multiplechoice survey on WTP for safe beef in which a preference for Japanese black cattle beef, other Japanese beef, Australian beef and U.S. beef was included as a variable. Each participant in our survey may have had different personal impressions about beef, ranging from expensive Japanese black cattle beef to other kinds of relatively cheap Japanese beef; this is likely to be represented by their stated WTP and anxiety level. However, we have also demonstrated that WTP was influenced by household income and by the preference for beef, as shown in Table 4, which may also be influenced by the image of beef. Therefore, we adjusted the WTP for household income and preference for beef, which should avoid possible effects of different personal image of beef. Further studies are needed to assess the WTP for safe beef in which detailed classifications of the source of the beef are included as variables.

In terms of the roles of newspaper articles in risk communications, Bauer et al. [16] prepared a report for the World Health Organization Europe. In this report, they counted the number of newspaper articles in four countries (UK, Germany, Italy, and Finland) and the number of characters used in those articles. They found that when the UK government publicly announced that BSE could also infect human beings in March 1996, the number of related newspaper articles greatly increased in all four countries. Similarly, the number of newspaper reports increased in
2000 and 2001 when BSE was found in Germany, Italy, and Finland. These researchers also examined the salient features of those articles and concluded that the role of the mass media was likely to contribute to the formation of a public opinion rather than to respond to real-time events.

The participants in our survey were asked to state their impressions of the newspaper articles written more than 5 years before. Consequently, public awareness of BSE may have declined in the intervening period, and the results of this survey may not fully reflect the impact of these articles during the panic period. In addition, there is a sample bias because all participants were Internet users.

Based on our results, we have come to the following conclusions. First, the reasons for the anxiety reflect the content of each article, as shown in Table 2, indicating that the content was well understood. Second, as the number of read articles increased from Group A to Group C, the level of anxiety decreased. Based on these results, it can be assumed that the anxiety of general consumers can be reduced if they receive appropriate information by reading articles. Unlike TV programs that repeatedly report the same news, newspapers contain more and diverse content as the number of articles increase. However, in this survey, the effects of the articles selected could not be revealed because we did not examine how the contents of the articles affected the responses before their selection and presentation to respondents. Nevertheless, we conclude that access to more articles provides more information and can decrease anxiety. In addition, the content of the articles provided may affect the WTP for safe beef. The results may include some bias toward the presence and number of children, ages of children, frequency of cooking at home, and education, and they may be limited because of these factors. Further studies are needed to determine the relationships between article content and anxiety.

Overall, the findings of this study indicate that newspapers provide an effective risk communication tool by which to provide an appropriate volume of truthful articles on a regular basis.

Acknowledgments The present study was funded by the Food Safety Commission of the Cabinet Office, Government of Japan. The authors thank Mako Yabunouchi for assisting with this study.

\section{Appendix: Summary of the six articles presented (originally published in Japanese-language newspapers)}

\section{Article 1 (reported on September 11, 2001 in Yomiuri)}

A cow, which was fed in Chiba prefecture, was diagnosed with BSE. This was the first case of BSE disease to occur 
in Japan. The cow had become unable to stand up in early August. Milk from this cow had been included in shipments to consumers. The Ministry of Agriculture, Forestry, and Fisheries (MAFF) said that milk intake would never cause infection in humans.

Article 2 (reported on September 13, 2001 in Asahi)

The farmer who bred the first BSE-infected cow had already sold 72 cows in 2001. All of the breeding farmers asserted that they did not feed meat-and-bone meal to their cows. The MAFF decided to conduct a nationwide survey of all cows and cattle with BSE-related neurological symptoms.

\section{Article 3 (reported on September 15, 2001 in Mainichi)}

The MAFF's statement that the BSE-infected cow was destroyed turned out to be misleading. The cow was actually processed to bone-meal feed at a factory producing feeds. The administrative authority of Chiba prefecture found that part of the bone meal feed was distributed to the market and the remaining feed had been stored by a trader.

\section{Article 4 (reported on September 15, 2001 in Asahi)}

The Ministry of Health, Labour, and Welfare (MHLW) has decided to conduct checks on all of the approximately 1 million cows and cattle aged $\geq 30$ months. This test standard is as strict as that of the EU. In the past, only cows and cattle with neurological symptoms were subjected to the test in Japan. The new standard will likely entail a high expenditure, estimated at a total of 25 million dollars.

\section{Article 5 (reported on October 13, 2001 in Asahi)}

The MHLW was confused in disclosing the positive results of a screening test for BSE. In the screening tests, falsepositive results occur in one or two cows per 1,000 cows. The MHLW intended not to publicly disclose the results of the screening tests until its decisive result became clear. However, the administrative authority of Tokyo prefecture disclosed the positive result soon after it was detected in the screening test. Eventually, the MHLW decided to set a direction and announced that it would disclose all screening results.

Article 6 (reported on October 17, 2001 in Asahi)

The MAFF insisted that the disclosure of false-positive results in the screening tests would cause harmful rumors.
According to this opinion, the MHLW changed its policy of not disclosing screening test results. The MHLW banned shipment of screening-positive beef until a negative result was finally obtained in further testing.

\section{References}

1. Brown P. Bovine spongiform encephalopathy and variant Creutzfeldt-Jakob disease. Br Med J. 2001;322:841-4.

2. Watts J. Bovine spongiform encephalopathy case found in Japan. Lancet. 2001;358:991.

3. Imamura $T$, Ide $H$, Yasunaga $H$. History of public health crises in Japan. J Public Health Policy. 2007;28:221-37.

4. Takeshita $H$. The quantitative analysis of the effect of health information on food consumption. J Rural Econ. 1999;71:61-70.

5. Sawada M. Food safety information and food expense-case studies on incidents of mad cow disease and O157. Nihon Nogyo Keizai Gakkai Ronbunshu. 1998;98:72-74.

6. Iwamoto H, Sato K, Sawada M. Consumers' willingness-to-pay for beef distributed under the traceability system. Nihon Nogyo Keizai Gakkai Ronbunshu. 2003;314-316.

7. McCluskey JJ, Grimsarud KM, Ouchi H, Wahl TI. Bovine spongiform encephalopathy in Japan: consumers' food safety perceptions and willingness to pay for tested beef. Aust J Agric Resour Econ. 2005;49:197-209.

8. Yamane F. Estimation of change in consumer welfare caused by the revision of age criterion for BSE testing: hypothetical revealed preference method using survey data. J Rural Econ. 2008;80(1):1-16.

9. Giamalva JN, Redfern M, Bailey WC. Dietitians employed by health care facilities preferred a HACCP system over irradiation or chemical rinses for reducing risk of foodborne disease. J Am Diet Assoc. 1998;98:885-8.

10. Frenzen PD, DeBess EE, Hechemy KE, Kassenborg H, Kennedy M, McCombs K, et al. Consumer acceptance of irradiated meat and poultry in the United States. J Food Prot. 2001;64:2020-6.

11. van der Pol M, Ryan M, Donaldson C. Valuing food safety improvements using willingness to pay. Appl Health Econ Health Policy. 2003;2:99-107.

12. Miller D. Risk, science and policy: definitional struggles, information management, the media and BSE. Soc Sci Med. 1999;49:1239-55.

13. Verbeke W. Consumer reactions and economic consequences of the BSE crisis. Verh K Acad Geneeskd Belg. 2001;63:483-92.

14. de Jonge J, van Trijip H, Renes RJ, Frewer L. Understanding consumer confidence in the safety of food: its two-dimensional structure and determinants. Risk Anal. 2007;27:729-40.

15. Aizaki H, Sato K, Kikkawa T, Sawada M. Effect of attitudes concerning food safety on choice behavior of beef: a choice experiment including social-psychological factors. Jpn J Farm Manage. 2004;42:22-32.

16. Bauer MW, Howard S, Hagenhoff V, Gasperoni G, Rusanen M. The BSE and CJD crisis in the press. In: Dora C, editor. Health, hazards and public debate: lessons for risk communication from the BSE/CJD saga. Copenhagen: WHO Regional Office for Europe; 2006. p. 126-64. 